\title{
L2 LEARNERS' VOCABULARY DEVELOPMENT IN INCIDENTAL/INTENTIONAL LEARNING CONDITIONS: ROLE OF PERSONALITY TYPES
}

\author{
Mahmood Hashemian \\ English Department, Faculty of Letters \& Humanities, Shahrekord University, Iran \\ Email: hashemin-m@sku.ac.ir
}

\begin{abstract}
APA Citation: Hashemian, M. (2020). L2 learners' vocabulary development in incidental/intentional learning conditions: Role of personality types. Indonesian Journal of Learning and Instruction, 3(1), 27-36. doi: 10.25134/ijli.v3i1.3005.
\end{abstract}

\begin{abstract}
This study investigated the effect of incidental/intentional learning and the effect of personality types on participants' vocabulary learning. The sample involved 69 L2 learners. After completing a vocabulary test, they were placed into 2 groups. Both groups had to read 3 texts, with only the intentional group being informed about an upcoming posttest. Some vocabulary activities were provided for the intentional participants, drawing their attention to word meanings. The incidental group, however, was required to answer some comprehension questions. The posttest and Myers-Briggs Type Indicator were administered after the treatment. Results revealed that the intentional group outperformed the incidental one. The only personality dimension found to influence vocabulary learning was extroversion/introversion. It can be suggested that the intention to learn can encourage L2 learners to attend to the meanings of the words. Moreover, the introverts were believed to have higher concentration and problem-solving ability. Results can help L2 teachers reach a better understanding of vocabulary learning. Also, an awareness of L2 learners' individual differences can help teachers adjust their classes and adopt their materials accordingly.

Keywords: incidental vocabulary learning; intentional vocabulary learning; personality types.
\end{abstract}

\section{INTRODUCTION}

Learning vocabulary has always been one of the challenges facing L2 learners and is considered as a troublesome task by both L2 learners and teachers. As pointed out by Schmitt (2008), it is no doubt that learning vocabulary is essential for language mastery. Therefore, vocabulary learning plays a vital role in L2 learning. However, until recently, vocabulary learning had received little attention (Wu, 2009). Even in the communicative approach, the focus is on the communicative functions and the knowledge of lexicon comes next.

In recent years, there has been an increasing number of studies on vocabulary learning (e.g., Li, 2013; Marashi \& Azarmi, 2012; Nassaji, 2004). Researchers have investigated different ways and techniques of teaching and learning vocabulary (Lee, 2003; Thornbury, 2003), including incidental and intentional learning. Incidental and intentional learning are twolearning modes investigated in several studies (e.g., Moradian Fard, 2005; Yali, 2010). Incidental learning can be defined as "the type of learning that is the byproduct of doing or learning something else," whereas intentional learning is defined as "being designed, planned for, or intended by teacher or student" (Hatch \& Brown,
1995, p. 368). So far, there is still doubt regarding which type of learning is more effective. The present study was an attempt to further clarify the issue and contribute to the literature.

Personality is another issue that has been addressed in this study. Recent research in the field of language learning has shown that L2 learners bring different learning styles and personality traits with themselves to the classroom and that individual differences can affect their academic achievement and language learning (e.g., Carrell, Prince, \& Astika, 1996; Dewaele \& Furnham, 2000; Qomarudin, 2010). Pervin and John (2001) define personality as an individual's characteristics that "account for consistent patterns of feeling, thinking, and behaving" (p. 4). There are inconsistencies in the findings of studies conducted on the role of personality, indicating a need to further examine the matter. Therefore, the present study sought to answer three questions:

1. Do incidental and intentional learning conditions affect L2 learners' performance on a vocabulary test?

2. Do personality types, as determined by MBTI, have an impact on L2 learners' performance on a vocabulary test? 
3. Do personality types, as determined by MBTI, moderate the effect of the two types of learning conditions (i.e., incidental and intentional) on L2 learners' performance on a vocabulary test?

There are two popular views on what it means to learn a language - one holding that it involves years of intentional study and committing thousands of words and dozens of grammar rules to memory deliberately, and another view holding that much of the burden of intentional learning can be removed through incidental learning, in which the learner's attention is focused on the meaning rather than on the form.

The concept of incidental and intentional learning was mainly considered as a methodological aspect of research design when it first appeared in psychology and, later in SLA, referred to "the presence or absence of an explicit instruction to learn" (Hulstijn, 2003, p. 354).

Hulstijn (2005) has offered operational definitions for these two types of learning. According to him, in intentional learning mode, before a learning task, participants are forewarned that they will be tested afterward on their retention of a particular type of information. In incidental learning mode, however, they are not informed of such a test.

In a study in 1981, Shelton and Newhouse found out that the learners who were exposed to the stimulus material in an incidental learning situation performed significantly better in a subsequent recall test than those who were simply instructed to learn the same material.

In another attempt to explore the issue of incidental and intentional learning, Moradian Fard (2005) divided the participants into two groups. The members of the experimental group were required to read eight short stories, containing 40 target word, during 10-15 min of each class session. The control group was not given any treatment and only read a list of target words out of context. Both groups were administered a posttest of the same words. According to the results, the experimental group outperformed the control group, indicating superiority for incidental learning.

Yan (2006), however, emphasized the same view Konopak et al. presented in 1987. The participants were divided into two groups and each received one of the two treatments: learning vocabulary incidentally through reading and memorizing words in wordlists. The intentional learning helped the learners to learn more words in both receptive and productive vocabulary knowledge; the incidental learning, however, resulted in better retention rates.

In Barcroft's study (2009), however, the intentional group performed better on the posttest. Both intentional and incidental groups were required to read an English passage containing 10 target words translated in the text. Vocabulary recall was higher when explicit instructions to learn new words were provided.

These findings are in line with Marashi and Azarmi (2012) and Li (2013) who found out that intentional learning condition led to significantly higher retention than incidental learning mode.

\section{Personality}

It is believed that having a deeper understanding of the concept of personality type can help to explain why L2 learners learn differently (Wilz, 2000). In order to better understand individuals' personalities, several questionnaires and inventories have been designed, including Eysenck Personality Types and Myers-Briggs Type Indicator (MBTI; Eysenck \& Eysenck, 1964; Myers, 1962).

Being the most widely used inventory, MBTI originates from Jung's (1990) theory of psychological types. Jung, a Swiss psychiatrist, developed a holistic framework for explaining psychological differences among people and proposed sets of opposite preferences: extroversion/introversion, sensing/intuition, and feeling/thinking. Later, Briggs Myers and Cook Brigs added another dimension to Jung's theory, namely judging/perceiving.

Different studies have been conducted on the effect of personality types on language learning, the results of which are inconsistent. In 1978, Naiman Frohlich, Stern, and Todesco carried out a study on personality variables and language learning, showing no correlation between extroversion and language test scores. His findings were quoted for two decades, but they were never challenged.

Myers and McCaulley (1985), however, found out a difference between extroverts' and introverts' learning preferences. According to them, extroverts prefer learning situations that involve social interaction and inductive approaches, whereas introverts tend to prefer learning situations in which they are alone or in small groups.

Myers and McCaulley (1985), however, found out a difference between extroverts' and introverts' learning preferences. According to them, extroverts prefer learning situations that involve social interaction and inductive 
approaches, whereas introverts tend to prefer learning situations in which they are alone or in small groups.

In 1998, Grace conducted a study on the effect of personality on L2 learners' vocabulary learning in ambiguous and nonambiguous contexts. As revealed by the results, the learners' personality types made no difference in their vocabulary learning.

Marefat (2006) conducted a study aimed at investigating the effect personality might have on writing ability. MBTI was employed to assess the learners' personality types. According to the results, the only dimension showing significant impact was sensing/intuition. It was revealed that the intuitive learners outperformed sensors in their writing skills.

In 2012, Mansouri Nejad, Bijami, and Ahmadi examined 30 L2 university students' writing ability and its relationship with extroversion/introversion. They found no significant correlation between personality and writing skill.

As illustrated above, research on personality types has been inconsistent and incongruent. Therefore, more empirical studies are necessary to find more conclusive results.

\section{METHOD}

A total of 91 intermediate Iranian L2 learners, attending different English institutes in Shahrekord (Iran), were selected and required to take a standardized $300 \mathrm{D}$ test of the Nelson English Language Tests (Fowler \& Coe, 1976) in an attempt to ensure their homogeneity in terms of their proficiency. Afterwards, 69 learners who scored between 1 standard deviation below and above mean, consisting of 59 females and 10 males, were selected and divided into two experimental groups: incidental and intentional.

The materials included the Nelson English Language Proficiency Test, a pretest, a posttest, three reading comprehension texts accompanied by related activities, and MBTI. The first test employed was the Nelson English Language Proficiency Test in order to ensure the participants' homogeneity in terms of language proficiency. This test includes 50 items, consisting of a cloze passage and multiple-choice items focusing on grammar, vocabulary, and pronunciation. It took, at most, $45 \mathrm{~min}$ to administer the test, after which the scores were calculated. Then, 69 learners were selected as the main participants.
The second instrument was a 25-item multiple-choice vocabulary test designed by the researchers to examine the participants' knowledge of the target words. The original test contained 30 items, testing the target words and six extra words. However, five items were removed after test validation. The test consisted of two parts: the first part requiring the respondents to fill in the blanks by choosing the best word that completes the sentence and the second part requiring them to choose the word that was closest in meaning to the underlined word. This test underwent expert judgment before administering. Then, the validity and reliability of the test were measured, which will be elaborated on in the following.

Moreover, a parallel test was designed to measure the participants' knowledge of the target words after the study. This test underwent expert judgment and a pilot study. As the result of the pilot study, the validity and reliability of the test were computed. As a result of validation, four items were removed from the posttest. One more item, which was not needed anymore, was deleted in order that it would be parallel to the pretest.

Four texts were selected from the book ACTIVE Skills for Reading: Book 1 (Anderson, 2009) to be employed in the study, one of which was later removed after the pilot study. The titles of the three texts were The World Oldest University, How Do You Celebrate, and Internet Hoaxes. The texts were presented to the participants. Each text was accompanied by some activities. The participants in the incidental group were required to answer some comprehension questions, so their attention would be focused on the content of the texts. They were not informed about an upcoming test. The participants in the intentional group, however, were warned about the posttest, so they would focus on learning the target words. They were also required to perform vocabulary activities, focusing their attention on the words. In the last session, the posttest was administered to all the participants.

The last instrument was the translated version of MBTI employed to determine the participants' personality types. MBTI assesses individuals' personality according to four categories: (1) extroversion vs. introversion, (2) sensing vs. intuition, (3) thinking vs. feeling, and (4) judging vs. perceiving. The instrument consists of 94 items, requiring the respondents to choose between two or three choices. The participants had to select the choices according to their preference toward the items. It should be 
mentioned that the reliability of MBTI is reported to be .82 for introversion/extroversion, .84 for sensing/intuition, .83 for thinking/feeling, and .86 for judging/perceiving (Woosley, 2001).

In order to explore the first research question, the participants were placed into two groups. Each group was assigned a different task, providing an appropriate condition for either incidental or intentional vocabulary learning.

During the first session of the study, all the participants completed a pretest, taking about 15 min. The test was specifically designed by the researchers in order to check the participants' knowledge of the target words.

One week later, the first text was presented to the participants. The meanings of the words were offered to the participants in a marginal L2 gloss. The aim of the glossing was to help the participants understand the meanings of the unfamiliar words without needing to ask or look up in a dictionary and avoid any interruption in the process of reading.

The participants in the incidental group were required to read the text and answer some questions, testing their comprehension of the text and drawing their attentions to its content. Following Hulstijn's (2005) operationalization of incidental and intentional learning, the participants were not informed about the posttest.

The participants in the intentional group, on the other hand, were required to do tasks which provided them with an intentional learning condition. For this purpose, the target words were in bold in the text. We warned the participants about an upcoming test on the bold-faced words. Moreover, the text was accompanied by vocabulary activities. There were two forms of activities: one requiring the participants to complete sentences with appropriate words and one asking them to match the words with their definitions.

The same procedure was done with the second and the third texts in the following sessions. Immediately after the last text, the posttest and MBTI were administered to all the participants.

\section{RESULTS AND DISCUSSION}

After the experiment, the data obtained from the pretest, the posttest, and the MBTI were fed into the SPSS program and several Analyses of Covariance (ANCOVA) were run to examine the research questions (see Table 1).

Table 1. Analyses of covariance summary for first research question

\begin{tabular}{lcccccc}
\hline \multicolumn{1}{c}{ Source } & $\begin{array}{c}\text { Type III Sum of } \\
\text { Squares }\end{array}$ & $\boldsymbol{D} \boldsymbol{f}$ & Mean Square & $\boldsymbol{F}$ & Sig. & $\begin{array}{c}\text { Partial Eta } \\
\text { Squared }\end{array}$ \\
\hline Group & 25.626 & 1 & 25.626 & 11.455 & .001 & .163 \\
Extroversion/ Introversion & 13.985 & 1 & 13.985 & 5.745 & .020 & .089 \\
Sensing/Intuition & 9.634 & 1 & 9.634 & 3.841 & .055 & .061 \\
Thinking/Feeling & .178 & 1 & .178 & .067 & .797 & .001 \\
Judging/Perceiving & 6.287 & 1 & 6.287 & 2.451 & .123 & .040 \\
Group * Extroversion/Introversion & 1.614 & 1 & 1.614 & .815 & .371 & .014 \\
Group * Sensing/Intuitive & .023 & 1 & .023 & .010 & .921 & .000 \\
Group * Thinking/Feeling & 1.629 & 1 & 1.629 & .724 & .398 & .013 \\
Group * Judging/Perceiving & 1.855 & 1 & 1.855 & .836 & .364 & .014 \\
\hline
\end{tabular}

In order to explore the first hypothesis and to see the probable effect of the treatment, a oneway between-groups ANCOVA was conducted (see Table 1). The type of learning condition (i.e., incidental vs. intentional) was the independent variable and the scores on the posttest were the dependent variable. The scores on the pretest were also considered as the covariate to control for individual differences.

Prior to the analysis, the necessary assumptions were checked to ensure that there was no violation of necessary assumptions. The significance value for the Levene's test of equality of error variances was larger than .05 , indicating that the assumption of equality of variances was not violated.

The results of ANCOVA indicated that after adjusting for pretest scores, there was a significant difference between the two types of learning $(\mathrm{p}=.001)$, revealing that the intentional group outperformed the incidental one. Table 2 offers adjusted means for the two groups, respectively. The results of ANCOVA are presented in Table 1. 
Table 2. Estimated marginal means for incidental and intentional groups

\begin{tabular}{lccccc}
\hline \multicolumn{1}{c}{ Group } & $\boldsymbol{N}$ & Mean & Std. Error & \multicolumn{2}{c}{$\mathbf{9 5 \% \text { Confidence Interval }}$} \\
\cline { 5 - 6 } & & & & Lower Bound & Upper Bound \\
\hline Incidental & 32 & $8.759^{\mathrm{a}}$ & .266 & 8.228 & 9.290 \\
Intentional & 30 & $10.057^{\mathrm{a}}$ & .274 & 9.508 & 10.606 \\
\hline
\end{tabular}

a. Covariates appearing in the model are evaluated at the following values: Pretest $=3.774$.

The results indicate superiority for the intentional learning condition. Therefore, the null hypothesis below is rejected:

$\mathrm{H}_{01}$ : Incidental and intentional learning conditions affect L2 learners' performance on a vocabulary test.

The purpose of the second research question was to explore the (probable) impact of different personality types on vocabulary learning, in general, without considering the effect of the incidental and intentional learning conditions. In order to do so, four ANCOVAs were conducted to assess each dimension of personality.
The following tables show the results of these statistical analyses. First, a one-way ANCOVA was run to compare the extroverted and introverted participants in terms of their posttest scores. Prior to the analysis, the necessary assumptions were checked. Table 3 show adjusted means for the two personality types. As depicted in Table 3, the numbers of the extroverts and introverts are 42 and 20. Table 1 reveals that significant value is .020 , which indicates the second null hypothesis related to the second question is rejected. Therefore, it can be suggested that extroversion and introversion are influencing factors in vocabulary learning.

Table 3. Estimated marginal means for extroverted and introverted groups

\begin{tabular}{lccccc}
\hline \multicolumn{1}{c}{ Group } & $\boldsymbol{N}$ & Mean & Std. Error & \multicolumn{2}{c}{$\mathbf{9 5 \%}$ Confidence Interval } \\
\cline { 4 - 6 } & & & & Lower Bound & Upper Bound \\
\hline Incidental & 42 & $9.048^{\mathrm{a}}$ & .244 & 8.561 & 9.535 \\
Intentional & 20 & $10.100^{\mathrm{a}}$ & .357 & 9.385 & 10.814 \\
\hline
\end{tabular}

a. Covariates appearing in the model are evaluated at the following values: PreTotalChanged2 $=3.774$.

The purpose of the second analysis was to investigate the influence of sensing and intuition types on learning vocabulary. After checking the necessary assumptions, ANCOVA was run, the results of which revealed that no significant difference was found between sensing and intuitive learners on their posttest scores $(\mathrm{p}=$ $.055)$. As shown in Table 4, the numbers of sensing and intuitive participants are 24 and 38, respectively, and the adjusted means for sensing the two personality types are 9.883 and 9.0 .

Table 4. Estimated marginal means for sensing and intuitive groups

\begin{tabular}{lccccc}
\hline Group & $\boldsymbol{N}$ & Mean & Std. Error & \multicolumn{2}{c}{$\mathbf{9 5 \%}$ Confidence Interval } \\
\cline { 5 - 6 } & & & & Lower Bound & Upper Bound \\
\hline Incidental & 26 & $9.883 \mathrm{a}$ & .323 & 9.236 & 10.530 \\
Intentional & 38 & $9.074 \mathrm{a}$ & .257 & 8.560 & 9.588 \\
\hline
\end{tabular}

a. Covariates appearing in the model are evaluated at the following values: PreTotalChanged $2=$ 3.7742 .

The next ANCOVA aimed at comparing the thinking and feeling participants in terms of their vocabulary learning. Table 5 shows that the number of the thinking and feeling participants are 34 and 28, respectively. According to the results of ANCOVA, there was no significant difference between the two personality types $(\mathrm{p}=$ .797), suggesting that this personality distinction does not influence vocabulary learning. The adjusted mean scores for the thinking and feeling participants are 9.338 and 9.446 , respectively:

Table 5. Estimated marginal means for thinking and feeling group

\begin{tabular}{lccccc} 
Group & $\boldsymbol{N}$ & Mean & Std. Error & \multicolumn{2}{c}{$\mathbf{9 5 \%}$ Confidence Interval } \\
\cline { 5 - 6 } & & & & Lower Bound & Upper Bound \\
\hline Incidental & 34 & $9.338 \mathrm{a}$ & .281 & 8.777 & 9.900 \\
Intentional & 28 & $9.446 \mathrm{a}$ & .309 & 8.827 & 10.065 \\
\hline
\end{tabular}


The last analysis for the second hypothesis considered the judging-perceiving distinctions. The results of ANCOVA $(\mathrm{p}=.123)$ indicated no significant difference between the judging and perceiving participants in terms of their posttest scores. As revealed in Table 6, of the participants, 46 are judgers and 16 are perceivers and the adjusted means for judgers and perceivers are 9.576 and 8.845 , respectively:

Table 6. Estimated marginal means for judging and perceiving group

\begin{tabular}{lccccc}
\hline Group & $\boldsymbol{N}$ & Mean & Std. Error & \multicolumn{2}{c}{ 95\% Confidence Interval } \\
\cline { 5 - 6 } & & & Lower Bound & Upper Bound \\
\hline Incidental & 46 & $9.576 \mathrm{a}$ & .236 & 9.103 & 10.049 \\
Intentional & 16 & $8.845 \mathrm{a}$ & .402 & 8.041 & 9.649 \\
\hline
\end{tabular}

a. Covariates appearing in the model are evaluated at the following values: PreTotalChanged $2=$ 3.7742 .

As revealed by the results of the above statistical analyses, the null hypothesis below was rejected with regard to the extroversionintroversion distinction:

$\mathrm{H}_{02}$ : Personality types, as determined by MBTI, do not have an impact on L2 learners' performance on a vocabulary test.

The third research question aimed at investigating the interaction between personality and incidental/intentional vocabulary learning. In order to investigate the influence of personality types on the effectiveness of these two types of learning, four two-way ANCOVAs were run in SPSS. The dependent variable was the posttest scores and the independent ones were personality types and the type of learning condition. The pretest scores were used as the covariate in this analysis.

First, a two-by-two between-groups ANCOVA was conducted to assess the effectiveness of the two learning conditions for the introverted and extroverted participants. As shown in Table 4.1, the interaction effect ( $p=$ .371) was not significant, suggesting that introverts and extroverts do not respond differently to incidental and intentional learning conditions. The adjusted means and the number of the introverts and extroverts in each group are presented in Table 7.

Table 7. Estimated marginal means for third research question-extroversion vs. introversion

\begin{tabular}{lcccccc}
\hline Group & Type & $N$ & Mean & Std. Error & \multicolumn{2}{c}{ 95\% Confidence Interval } \\
\cline { 4 - 6 } Incidental & Extroverted & 21 & $8.457 \mathrm{a}$ & .318 & Lower Bound & Upper Bound \\
& Introverted & 11 & $9.292 \mathrm{a}$ & .433 & 8.425 & 9.094 \\
\multirow{2}{*}{ Intentional } & Extroverted & 21 & $9.611 \mathrm{a}$ & .307 & 8.996 & 10.160 \\
& Introverted & 9 & $11.150 \mathrm{a}$ & .472 & 10.205 & 10.227 \\
& & & & & & 12.095 \\
\hline
\end{tabular}

a. Covariates appearing in the model are evaluated at the following values: PreTotalChanged $2=3.7742$.

Afterwards, another two-way ANCOVA was run to examine whether the sensing and intuitive participants respond differently to incidental and intentional learning conditions. The results of the analysis revealed a nonsignificant interaction effect $(p=.921)$. Therefore, being sensing or intuitive had not affected the posttest scores obtained by the participants in the incidental and intentional groups. Table 8 presents the adjusted means for each personality type in each group.

Table 8. Estimated marginal means for third research question-sensing vs. intuition

\begin{tabular}{lcccccc}
\hline Group & Type & $\boldsymbol{N}$ & Mean & Std. Error & \multicolumn{2}{c}{ 95\% Confidence Interval } \\
\cline { 6 - 7 } & & & & & Lower Bound & Upper Bound \\
\hline Incidental & Sensing & 5 & $8.990 \mathrm{a}$ & .687 & 7.615 & 10.364 \\
& Intuitive & 27 & $8.716 \mathrm{a}$ & .296 & 8.123 & 9.310 \\
Intentional & Sensing & 19 & $10.122 \mathrm{a}$ & .349 & 9.423 & 10.820 \\
& Intuitive & 11 & $9.945 \mathrm{a}$ & .470 & 9.005 & 10.886 \\
\hline
\end{tabular}

a. Covariates appearing in the model are evaluated at the following values: PreTotalChanged $2=3.7742$. 
Another ANCOVA was carried out regarding the thinking-feeling dimension. The interaction effect was not significant $(\mathrm{p}=.398)$, indicating that the thinking and feeling participants did not respond differently to the two types of learning conditions. Table 9 reveals the adjusted means for each personality type in each group.

Table 9. Estimated marginal means for third research question-thinking vs. feeling

\begin{tabular}{lcccccc}
\hline Group & Type & $\boldsymbol{N}$ & Mean & Std. & \multicolumn{2}{c}{ 95\% Confidence Interval } \\
\cline { 6 - 7 } & & & & Error & Lower Bound & Upper Bound \\
\hline Incidental & Thinking & 23 & $8.979 \mathrm{a}$ & .318 & 8.342 & 9.615 \\
& Feeling & 9 & $8.218 \mathrm{a}$ & .503 & 7.211 & 9.225 \\
Intentional & Thinking & 11 & $10.081 \mathrm{a}$ & .458 & 9.165 & 10.998 \\
& Feeling & 19 & $10.034 \mathrm{a}$ & .344 & 9.344 & 10.723
\end{tabular}

a. Covariates appearing in the model are evaluated at the following values: PreTotalChanged2 $=3.7742$.

The last analysis aimed at assessing the influence of judging and perceiving on the effectiveness of the incidental and intentional learning. The results of the analysis indicated a nonsignificant interaction effect $(\mathrm{p}=.158)$. Table 10 shows the adjusted means for the perceiving and judging participants in each group.

Table 10. Estimated marginal means for third research question-judging vs. perceiving

\begin{tabular}{lcccccc}
\hline Group & Type & $\boldsymbol{N}$ & Mean & Std. Error & \multicolumn{2}{c}{ 95\% Confidence Interval } \\
\cline { 6 - 7 } & & & & & Lower Bound & Upper Bound \\
\hline Incidental & Judging & 22 & $8.830 \mathrm{a}$ & .318 & 8.194 & 9.466 \\
& Perceiving & 10 & $8.600 \mathrm{a}$ & .476 & 7.648 & 9.553 \\
Intentional & Judging & 24 & $10.266 \mathrm{a}$ & .305 & 9.655 & 10.877 \\
& Perceiving & 6 & $9.225 \mathrm{a}$ & .609 & 8.006 & 10.443 \\
\hline
\end{tabular}

a. Covariates appearing in the model are evaluated at the following values: PreTotalChanged $2=$ 3.7742

The four statistical analyses indicated that the fourth hypothesis was not rejected:

$\mathrm{H}_{03}$ : Personality types, as determined by MBTI, do not moderate the effect of the two types of learning conditions (i.e., incidental and intentional) on L2 learners' performance on a vocabulary test.

\section{RESULTS AND DISCUSSION}

The findings of this study, indicating superiority for the intentional participants, are in line with previous studies conducted by Konopak et al. (1987), Barcroft (2009), Marashi and Azarmi (2012), Li (2013), and many other studies conducted in this regard.

Marashi and Azarmi (2012) claimed that the superiority of the intentional learning mode was due to the deeper mental analysis of the words, which result in a better retention. They suggest that L2 learners exposed to an intentional learning condition perform better than those who are not encouraged to undergo such mental analyses.

The significant gain of words in intentional learning can also be attributed to attention. The intentional group paid conscious attention to the words and their meanings, whereas the incidental participants' conscious attention was directed on the content of the texts.

In his input hypothesis, Krashen (1989) argues that focusing attention on meaning is the necessary and sufficient condition for acquisition to occur. However, some researchers like Ellis (1995) and Robinson (1995) argue against this view and claim that attention to both meaning and form is required for vocabulary learning. The findings of the present study indicate that directing attention to meaning is hardly enough to learn the words in a single exposure.

Moreover, the participants in the incidental group may have focused their attention on the texts and have paid no or only peripheral attention to the meanings of the words. Moreover, they may have disregarded the unfamiliar words entirely when they did not need them to comprehend the texts. Therefore, some of the target words may have gone unnoticed.

Moradian Fard conducted a study in 2005, the results of which were contrary to the findings of the present study. She argued that the incidental learning mode was more effective and helped the learners gain more words. However, she operationalized the intentional learning condition in a different manner than the one in the current 
study. The intentional group in Moradian Fard's study had to read a list of target words and their L1 equivalents. The superiority of incidental learning could be attributed to the fact that the participants in the intentional group learned the words out of context.

The second and third research questions examined the effect of personality types on the participants' scores on the posttest. According to the results, extroversion/introversion was the only dimension which was found to have an impact on the participants' test scores, without taking into account the learning modes. In both groups, the introverts managed to outperform the extroverts. This finding concurs with those studies by Ehrman (1994), Carrell et al. (1996), Kiany (1997), and Machnicka (2010), claiming the introverts to be better L2 learners. These studies have suggested that introverts have an advantage over extroverts with respect to learning, in general, and vocabulary, in particular.

Introverts possess a better concentration ability and are able to code new information more efficiently, leading them to a higher academic performance (Machnicka, 2010). On the other hand, extroverts tend to act quickly and hastily and tend to be impulsive at solving problems, talkative, and distracted, which makes them more likely to achieve a lower academic achievement (Hakimi, Hejazi, \& Gholamali Lavasani, 2011). These findings seem to be at odds with those studies which claimed that the extroverts were more successful than their introvert counterparts (e.g., Dewaele \& Furnham, 2000; Ghapanchi, Khajavy, \& Asadpour, 2011; Qomarudin, 2010). These researchers, as well as many others, concluded that extroversion is positively correlated with learning and suggested that extroverts are considered to be more proficient L2 learners.

However, one point to consider is that most of these studies have examined the relationship between extroversion and L2 learners' oral skills and proficiency. It has been stated in the literature that extroverts are sociable and open to new experiences, have a greater ability to deal with stressful situations, and possess better short-term memory in comparison with introverts (Dewaele \& Furnham, 2000; Ghapanchi et al., 2011). These characteristics cause extroverts to develop higher proficiency and perform better than introverts in situations which require face-to-face interactions.

Introverts, on the other hand, prefer situations with less pressure and stress. Moreover, they are naturally good at long-term memory (Hosseini
Naveh, Kaipour, \& Soltani, 2011) and are able to concentrate their resources on a subtask (Dewaele \& Furnham, 2000). Introverts, however, perform more efficiently in tasks which require concentration and ability to analyze and solve problems. In such tasks, such as written activities, L2 learners do not have to act on the spur of the moment and have more time to retrieve information from their long-term memory. As a result, due to these facts, the tasks in the present study were more effective for the introverted participants than the extroverted ones.

\section{CONCLUSION}

Learning vocabulary in an L2 is a long and difficult process; therefore, improving vocabulary learning and teaching techniques should be a high priority issue in every L2 course. The present study was an attempt to examine the effectiveness of incidental and intentional vocabulary learning. The results indicated superiority for the intentional participants.

As to the pedagogical implications of the findings, teachers and curriculum designers should provide opportunities for L2 learners to notice unfamiliar words and practice them in different activities.

The other variable investigated in this study was personality. Due to the fact that people with varying personality types perceive the world and interpret it in different ways, they may respond to the same situation differently. Therefore, personality traits are believed to influence how people learn and what they learn (Myres \& Myres, 1980).

Personality types are another variable explored in this study. The only significant difference was found between the extroverts and the introverts in learning the target words. Although extroverts are believed to be more proficient learners, introverts have higher concentration and problem-solving ability and act more successfully on activities which offer more time to retrieve information from their long-term memory and to analyze received information.

The present study could not take into considerations all the possible influencing variables and could not involve all aspects of vocabulary learning and personality. Therefore, it is recommended that further research be conducted in order to cover other aspects as well as to examine and cross-check the results of the current study.

Future research can replicate the current research in order to examine the findings obtained 
in the present study. However, it can involve a larger sample of L2 learners to check the generalizability of the results. Moreover, the sample in this study consisted of L2 learners studying English at the intermediate level in language institutes. In order to broaden the scope of this study, further research can be conducted involving non-English language learning classes and learners of different proficiency levels.

This study was an attempt to shed some light on intentional and incidental vocabulary learning and the effect of personality on these two learning modes; however, it was not devoid of limitations. The lack of time in language institutes hindered the researchers to increase the number of sessions, restricting the treatment to three texts only. Future research can consider investigating the same questions and employing the same procedure with more texts and activities.

In $\mathrm{L} 2$ research, input has been considered to be effective and helpful in L2 learning and in language programs. As the present study provided the participants with written input, other researchers can consider using oral input, which has been emphasized in recent research. In addition to input, output can be of crucial importance in making conclusions from the results.

Additionally, the participants were tested on their receptive knowledge, which is their ability to retain word meaning. In order to investigate L2 learners' productive knowledge, they can be required to produce output through sentencemaking tasks or writing compositions.

Future research can consider the inclusion of different vocabulary learning techniques/approaches and examine their effectiveness in helping L2 learners overcome the challenge of dealing with a large number of unfamiliar vocabularies in any language. Another direction for future research may involve different personality inventories, such as Eysenck Personality Questionnaire (Eysenck \& Eysenck, 1964), as well as other aspects of individual differences, including motivation, anxiety, language aptitude, language learning strategies, and so forth.

This section was an attempt to suggest ideas for future studies to those researchers who are interested in L2 learning and applied linguistics. However, given the complexity of vocabulary learning and personality types, there is no end to the potential research that could be conducted in these areas in future.
The findings of this study suggest that L2 teachers should be aware of different personality types and different teaching techniques that are most appropriate for each. It is advisable that L2 teachers adjust their classroom program in a way that involves a variety of teaching approaches and different types of tasks. They should inform L2 learners about their own personality and encourage them to utilize various learning strategies which are most appropriate for them.

\section{REFERENCES}

Alemi, M., \& Tayebi, A. (2011). The influence of incidental and intentional vocabulary acquisition and vocabulary strategy use on learning L2 vocabularies. Journal of Language Teaching and Research, 2(1), 81-98.

Anderson, N. J. (2009). ACTIVE skills for reading: Book 1. Massachusetts: HEINLE.

Barcroft, J. (2009). Effects of synonym generation on incidental and intentional L2 vocabulary learning during reading. TESOL Quarterly, 43(1), 79-103.

Carrell, P. L., Prince, M. S., \& Astika, G. G. (1996). Personality types and language learning in an EFL context. Language Learning, 46(1), 75-99.

Dewaele, J.-M., \& Furnham, A. (2000). Personality and speech production: A pilot study of second language learners. Personality and Individual Differences, 28, 355-365.

Ehrman, M. E. (1994). The type differentiation indicator and adult foreign language learning success. Journal of Psychological Type, 30(1), 10-29.

Ellis, N. (1995). Consciousness in second language acquisition: A review of field studies and laboratory experiments. Language Awareness, 4, 123-146.

Eysenck, H. J., \& Eysenck, S. B. G. (1964). Manual of the Eysenck personality inventory. London: Hodder and Stoughton.

Fowler, W. S., \& Coe, N. (1976). Nelson English language tests. London: Bulter \& Tannerltad.

Ghapanchi, Z., Khajavy, G. H., \& Asadpour, S. F. (2011). L2 motivation and personality as predictors of the second language proficiency: Role of the big five traits and L2 motivational self-system. Canadian Social Science, 7(6), 148155.

Grace, C. (1998). Personality type, tolerance of ambiguity, and vocabulary retention in CALL. CALICO Journal, 15, 19-45.

Hakimi, S., Hejazi, E., \& Gholamali Lavasani, M. (2011). The relationships between personality traits and students' academic achievement. Procedia - Social and Behavioral Sciences, 29, 836-845.

Hatch, E., \& Brown, C. (1995). Vocabulary, semantics, and language education. New York: Cambridge University Press. 
Hosseini Naveh, M., Kaipour, R., \& Soltani, R. (2011). The relationship among extraversion tendency, vocabulary learning strategies, and reading comprehension of EFL undergraduates in Kerman province. Studies in Literature and Language, 3(2), 104-110.

Hulstijn, J. (2003). Incidental and intentional learning. In C. J. Doughty \& M. H. Long (Eds.), The handbook of second language acquisition, 20-38. London: Blackwell Publishing.

Hulstijn, J. (2005). Theoretical and empirical issues in the study of implicit and explicit second language learning: Introduction. Studies in Second Language Acquisition, 27, 129-140.

Jung, C. G. (1990). Psychological types. Princeton, NJ: Princeton University Press.

Kiany, G. (1997). Extraversion and pedagogical setting as sources of variation in different aspects of English proficiency. United Kingdom: University of Essex.

Konopak, B., Sheard, C., Longman, D., Lyman, B., Slaton, E., Atkinson, R., et al. (1987). Incidental versus intentional word learning from context. Reading Psychology: An International Quarterly, $8(1), 7-21$.

Krashen, S. (1989). We acquire vocabulary and spelling by reading: Additional evidence for the input hypothesis. The modern language journal, 73(4), 440-464.

Lee, S. H. (2003). ESL learners' vocabulary use in writing and the effects of explicit vocabulary instruction. System, 31(4), 537-561.

Li, Q. (2013). Incidental and intentional vocabulary learning: A case study of meaning-given, meaning-inferred with $\mathrm{MC}$, and pure meaninginferred methods on the retention of L2 word meanings in a Chinese university. Education Journal, 2(4), 138-148.

Machnicka, J. (2010). The role of the personality variables of introversion and extraversion and language aptitude in the proficiency of English as a foreign language Unpublished master's thesis, Adam Mickiewicz University, Poland.

Mansouri Nejad, A., Bijami, M., \& Ahmadi, M. R. (2012). Do personality traits predict academic writing ability? An EFL case study. English Linguistics Research, 2, 145-152.

Marashi, H., \& Azarmi, A. (2012). The comparative effect of presenting words in semantically related and unrelated sets in intentional and incidental learning contexts on Iranian EFL learners' vocabulary learning. Journal of Second Language Teaching and Research, 1(2), 71-89.

Marefat, F. (2006). Students' writing and their personality type. Reading Matrix, 6, 33-38.

Moradian Fard, F. (2005). Incidental vocabulary learning through reading for pleasure among Iranian high school students. Unpublished master's thesis, The University of Isfahan, Iran.
Myers, I. B. (1962). The Myers-Briggs type indicator. Palo Alto, CA: Consulting Psychologists Press.

Myers, I. B., \& McCaulley, M. H. (1985). Manual: A guide to the development and use of the MyersBriggs Type Indicator. Palo Alto, CA: Consulting Psychologists Press.

Myers, I. B., \& Myers, P. B. (1980). Gifts differing: Understanding personality type. California: Consulting Psychologists Press.

Naiman, N., Frohlich, M., Stern, H. H., \& Todesco, A. (1978). The good language learner. Toronto: Ontario Institute for Studies in Education.

Pervin, L. A., \& John, O. P. (2001). Personality: Theory and research ( $8^{\text {th }}$ ed.). New York: John Wiley.

Qomarudin, A. (2010). Correlation between extraversion personality and writing skill. Unpublished doctoral dissertation, Diponegoro University, Semarang.

Robinson, P. (1995). Attention, memory, and the noticing hypothesis. Language Learning, 45, 283 331.

Schmitt, N. (2008). Review article: Instructed second language vocabulary learning. Language Teaching Research, 12(3), 329-363.

Shelton, D., \& Newhouse, R. C. (1981). Incidental learning in a paired-associate task. The Journal of Experimental Educational, 36-38.

Thornbury, S. (2003). Teaching vocabulary using short texts. Asian EFL Journal, 5(2), 230-234.

Wilz, B. (2000). Relationship between personality type and Grade Point Average of technical college students. Unpublished master's thesis, University of Wisconsin-Stout, Wisconsin.

Woosley, E. R. (2001). A look at the relationships between MBTI psychological types and mode conflict styles. Unpublished master's thesis, University of Wisconsin-Stout, Wisconsin.

Wu, L. (2009). Incidental English vocabulary studying in L2 learning: A study of learning and teaching English vocabulary in a college in China. Unpublished doctoral dissertation, Kristianstad University.

Yali, G. (2010). L2 vocabulary acquisition through reading: Incidental learning and intentional learning. Chinese Journal of Applied Linguistics, 33(1), 74-93.

Yan, X. P. (2006). Effects of the incidental and intentional learning on vocabulary retention. Unpublished master's thesis, Guangdong University of Foreign Studies, China. 